\title{
Reactive Power Operation Analysis of a Single-Phase EV/PHEV Bidirectional Battery Charger
}

\author{
Mithat C. Kisacikoglu ${ }^{1}$, Burak Ozpineci ${ }^{1,2}$, and Leon M. Tolbert ${ }^{1,2}$ \\ mkisacik@utk.edu, tolbert@utk.edu \\ ${ }^{1}$ Dept. of Electrical Engineering and Computer Science \\ The University of Tennessee \\ Knoxville, TN 37996-2100 \\ ozpinecib@ornl.gov \\ ${ }^{2}$ Power and Energy Systems Group \\ Oak Ridge National Laboratory \\ Oak Ridge, TN 37831
}

\begin{abstract}
More battery powered electric vehicles (EVs) and plug-in hybrid electric vehicles (PHEVs) will be introduced to the market in 2011 and beyond. PHEVs/EVs potentially have the capability to fulfill the energy storage needs of the electric grid by supplying ancillary services such as reactive power compensation, voltage regulation, and peak shaving since they carry an on-board battery charger. However, to allow bidirectional power transfer, the PHEV battery charger should be designed to manage such reactive power capability. This study shows how bidirectional fourquadrant operation affects the design stage of a conventional unidirectional charger and the operation of the battery pack. Mainly, the subjects that are discussed are the following: required topology updates, dc link capacitor (voltage and current), ac inductor (current), rectifier (power loss), and battery pack (voltage and current).
\end{abstract}

Keywords - Battery, bidirectional charger, charger, electric vehicle, EV, PHEV, reactive power, V2G.

\section{INTRODUCTION}

According to the international energy outlook report, the transportation sector is going to increase its share in world's total oil consumption by up to $55 \%$ by 2030 [1]. Therefore, the technologies related to reducing the oil consumption have one of the utmost challenges in today's vehicle research. Recently, alternative technologies have started to demonstrate market penetration owing to the introduction of plug-in hybrid electric vehicles (PHEVs) and all-electric or battery electric vehicles (EVs or BEVs) [2-6]. While they have an increased cost barrier at this time (not to mention the lack of a proven market demonstration of the technology), they exhibit a more efficient way of utilizing the available energy source from well-to-wheel, provide a more reliable fuel supply, and introduce a cleaner atmosphere especially to the densely populated urban cities.

PHEVs/EVs carry a battery pack that has a larger energy capacity $(>4 \mathrm{kWh})$ compared to conventional hybrid electric vehicles (HEVs) which requires external charging of the battery pack (internal charging would refer to regenerative charging of the battery as is the case in an HEV). Therefore, these vehicles carry a charger (usually a separate circuit than the motor traction drive) that converts the grid ac voltage to dc for the specific battery needs.

The integration of PHEVs and EVs into the electric grid at the residential distribution level is of great importance considering the rating of the charging power $(1-3 \mathrm{~kW})$. Studies point out that control of the chargers play an important role in the stable operation of the utility. For example, one scenario assumes the connection of four PHEVs in a neighborhood without any coordination to a $25 \mathrm{kVA}$ transformer while the transformer already operates with $80 \%$ of its full power rating at peak power hours [7]. This study showed a $10-50 \%$ reduction in transformer service lifetime. The increased power demand of these vehicles will also contribute to the increased transmission and distribution losses, and stability issues. However, the advanced design and control of chargers may help to alleviate the aforementioned problems.

Today, some of the residential loads in a house require reactive power for their operation such as the washing machine, refrigerator, and microwave oven. For instance, a microwave oven requires 400-500 VAR and a washing machine, depending on its cycle, requires $700-800$ VAR. Although, the customer is not billed for the consumption of reactive power, non-unity power factor operation causes extra losses at the power transmission and distribution system.

The charger can support the grid in several ways that can be listed as follows: a) time of day based coordination of the charging power, b) regulation of reactive power when connected to the grid, and c) sending power back to the grid when there is a need for peak shaving. In the literature, there are various studies that analyze the value and impact of these potential assets on the utility grid. On the other hand, the study in this paper investigates effects of the above operation principles on the design and control stage of the charger, and operation of the battery. The required updates in the charger will be summarized and the impact on the battery operation (if any) will be explained. The adverse effects of these operations (if any) on the manufacturing stage of the charger and lifetime of the battery and charger system components will be investigated. 
The following section provides a background regarding $\mathrm{PHEV} / \mathrm{EV}$ charging and chargers. Section III describes one specific application of chargers: reactive power operation. The following design parameters are investigated in terms of the effect of reactive power operation compared to baseline charging operation on the system: circuit topology and control, dc link capacitor, ac boost inductor, rectifier power loss, and battery pack. Section IV includes the simulation study of the charger to verify the analysis results. The last section lists important conclusions from this study.

\section{BATTERY CHARGERS}

\section{A. Battery Charging Profiles}

There are three main battery technologies used in HEVs and PHEVs/EVs. These are lead-acid, nickel metal hydride (NiMH), and lithium-ion (Li-ion) technologies. However, Li-ion battery cells are expected to become the viable energy storage devices for coming generations of PHEVs/EVs [8].

The common charging profiles used in the industry for Li-ion batteries are constant current (CC) and constant voltage $(\mathrm{CV})$ charging. During $\mathrm{CC}$ charging the current is regulated at a constant value until the battery cell voltage reaches a certain voltage level. Then, the charging is switched to CV charging and the battery is charged with a trickle current applied by a constant voltage output of the charger. Li-ion batteries with lithium-cobalt-oxide (LCO) cathode composition, which is mostly used in consumer applications (cell phone, camera, mp3 players, etc), have the charging profile shown in Fig. 1. These battery cells have a maximum charging voltage of $4.2 \mathrm{~V}$.

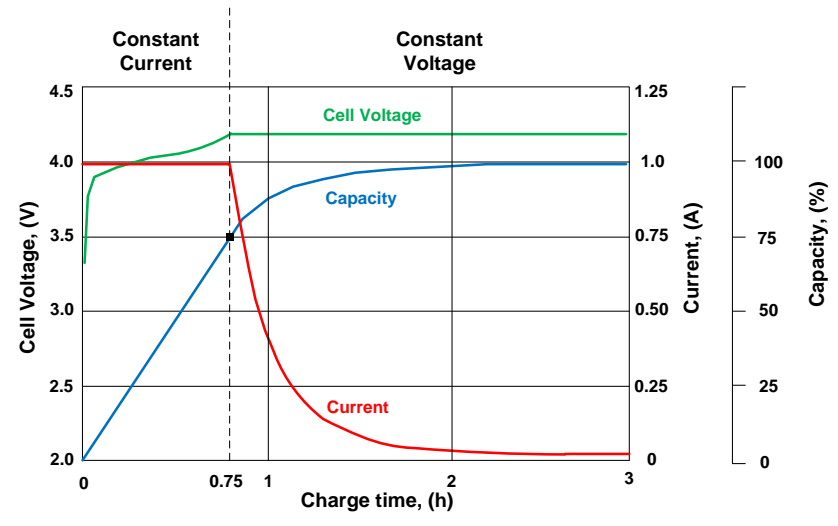

Fig. 1. Li-ion LCO battery CC-CVcharging profile [9].

One observation from the charge profile is that the battery cell requires around $50 \mathrm{~min}$ to finish $\mathrm{CC}$ charging phase starting from $0 \%$ SOC with $1 C$ charging current. $C$ stands for the rated charge current of the battery cell that will fully charge the battery in one hour. $N \cdot C$ is a charge rate equal to $N$ times the rated charging current where $N$ is a real number. The battery reaches $75 \% \mathrm{SOC}$ at the instant when the charger switches from $\mathrm{CC}$ to $\mathrm{CV}$ charging. The $\mathrm{CV}$ charging takes around $2 \mathrm{~h} 40 \mathrm{~min}$ resulting in a total charge time of $3.5 \mathrm{~h}$ [9]. Therefore the charge time required to charge the battery cell up to $75 \%$ SOC is $25 \%$ of the total charge time. In comparison, to cover only $25 \%$ the SOC, the charger needs to charge for $75 \%$ of total charge time during $\mathrm{CV}$ charging.

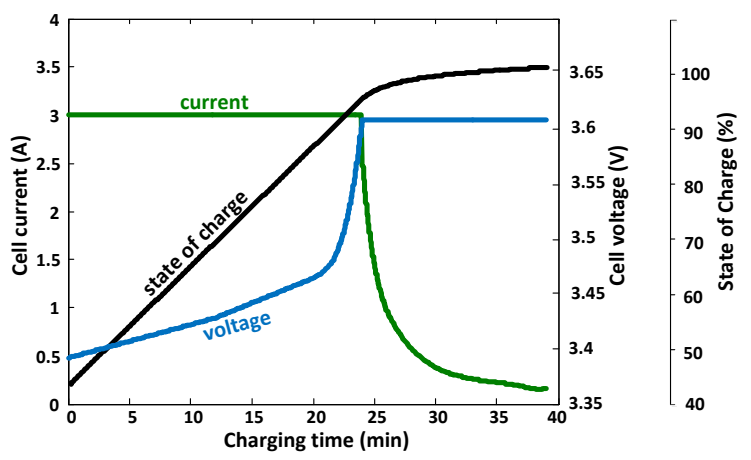

Fig. 2. Li-ion LFP battery CC-CV charging profile.

In comparison, lithium-ion batteries with a cathode structure composed of lithium iron-phosphate (LFP) are more widely used in automotive applications. They present a different charging profile compared to LCO batteries because of the difference in the chemical structure. A single cell charging experiment of an LFP type battery showed that $\mathrm{CC}$ charging stage takes $75 \%$ of the total charging time whereas CV charging occupies $25 \%$ of the total charging time as shown in Fig. 2. The charging rate was again $1 C$. The behavior is exactly opposite to the LCO batteries.

\section{B. Charging Levels}

There are three levels based on the voltage and current ratings used to charge a vehicle battery: Level 1, Level 2 and dc charging. However, only Level 1 and Level 2 have been standardized so far [10]. DC charging, or previously known as Level 3 charging, is still under development [10]. Fig. 3 shows the US standard outlet voltage and current ratings. Level 2 charging is much more preferred because of reduced charging time compared to Level 1 charging. This method employs standard 208-240 Vac single phase power outlet that has a continuous current rating less than 80 A [10]. For example, Nissan Leaf EV has a total of $8 \mathrm{~h}$ charging time using its $3.3 \mathrm{~kW}$ on-board charger to fully charge its $24 \mathrm{kWh}$ depleted battery pack [6]. Also, it takes around $4 \mathrm{~h}$ to fully charge the depleted $16 \mathrm{kWh}$ Chevrolet Volt PHEV battery [5].

Another charging method is fast charging or $\mathrm{dc}$ charging. At these charging stations, ac voltage is converted to dc off the vehicle and the vehicle is dc coupled to the charging station. Charging power can go up to much higher values compared to the on board charging. Therefore, it will help vehicles to be charged in shorter amount of times. As an example of decreased charging time for this type of station, Nissan Leaf EV will be 
charged with an off-board quick charge station in $30 \mathrm{~min}$ from a depleted SOC to $80 \%$ SOC [6]. However, decreased battery lifetime is an issue because of the increased heat generation of the batteries at higher rates of current charging.

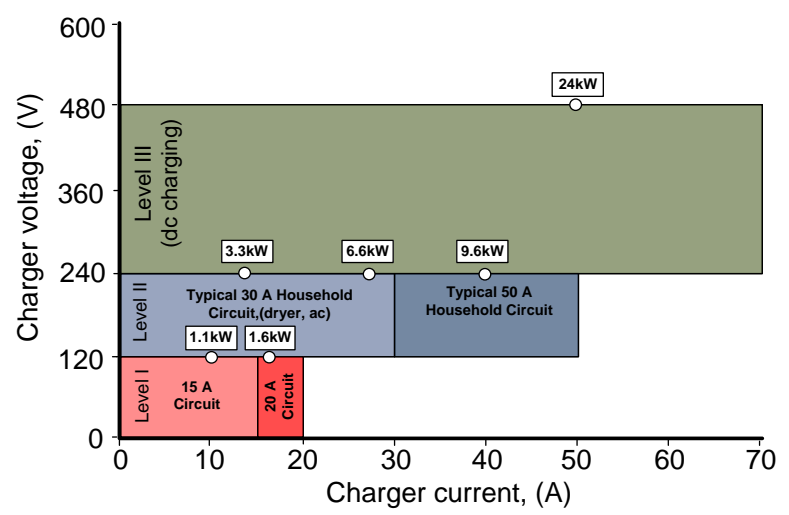

Fig. 3. Charging level map with respect to receptacle voltage and current ratings for US outlets [11].

\section{Charger Classifications}

Since the inception of the first EVs, there have been many different charging systems proposed. Due to many different configurations of the chargers, it is required to classify them based on some common design and application features. Table 1 lists five different methods of classifying chargers.

The chargers can be classified based on the circuit topologies. A dedicated circuit solely operates to charge the battery. In comparison, the traction inverter drive can serve as the charger at the same time when the vehicle is not working and plugged into the grid for charging. This option is commonly known as integral/integrated chargers.

A second classification is the location of the charger. Carrying the charger on-board greatly increases the charging availability of the vehicle. Off-board chargers can make use of higher amperage circuits and can charge a vehicle in a considerably shorter amount of time.

Third is the connection method. Conductive charging contains metal to metal contact, inductive charging connects ac grid to vehicle indirectly via a take-apart high frequency transformer, and mechanical charging replaces the depleted battery pack with a full one in battery swap stations.

Fourth, the electrical waveform at the connection port of the vehicle to the grid can be either a dc connection or an ac connection. Currently, the PHEVs and EVs in the market employ an ac connection type. However, in the future the availability and commonality of the dc sources may change the connection type.

Last, the charger can deliver power in unidirectional way by just charging the battery. More advanced designs introduce bidirectional power transfer. Again, all of the chargers in the market employ unidirectional chargers currently. More details and comparison of different type of chargers are investigated in [12].

Table 1. Charger classification summary.

\begin{tabular}{|l|l|}
\hline Classification type & Options \\
\hline Topology & Dedicated, Integrated \\
\hline Location & On-board, Off-board \\
\hline Connection type & Conductive, Inductive, Mechanical \\
\hline Electrical waveform & AC, DC \\
\hline Direction of power flow & Unidirectional, Bidirectional \\
\hline
\end{tabular}

\section{EFFECT OF REACTIVE POWER OPERATION ON THE CHARGER COMPONENTS AND BATTERY}

The charger used in this study is composed of a fullbridge inverter and a half bridge bidirectional dc-dc converter as shown in Fig. 4. Reference [12] lists different topologies other than what is shown in Fig. 4 that can be used for bidirectional charger application. This paper analyzes the topology (in Fig. 4) which is operated in unidirectional and bidirectional modes to show how the component parameters and system variables change with different operation modes such as reactive power operation.

The charger in Fig. 4 operates either as a current source or a linear load based on its operation mode. The ac-dc converter and its modulation enable the reactive power operation of the system. Fig. 5 also shows the operation quadrants of the charger. The topology is able to work in all four quadrants and the corresponding operation modes are listed in Table 2.

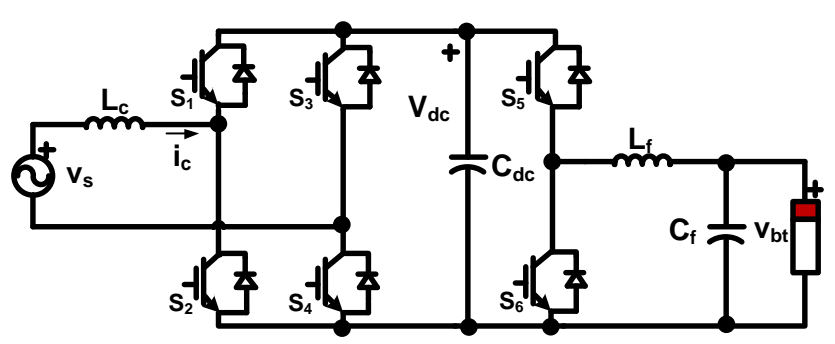

Fig. 4. Bidirectional charger schematic.

Table 2. Charger operation modes.

\begin{tabular}{|c|c|c|c|}
\hline$\#$ & $\mathbf{P}_{\mathbf{s}}$ & $\mathbf{Q}_{\mathbf{s}}$ & Operation Mode of the Charger \\
\hline 1 & Zero & Positive & Inductive \\
\hline 2 & Zero & Negative & Capacitive \\
\hline 3 & Positive & Zero & Charging \\
\hline 4 & Negative & Zero & Discharging \\
\hline 5 & Positive & Positive & Charging and inductive \\
\hline 6 & Positive & Negative & Charging and capacitive \\
\hline 7 & Negative & Positive & Discharging and inductive \\
\hline 8 & Negative & Negative & Discharging and capacitive \\
\hline
\end{tabular}

Based on the analysis of operation modes \#3 and \#4 in Table 2, they are actually the same since the only difference is the power flow direction. The utility grid 
usually needs capacitive reactive power, but just to show the operation capability, the inductive operation of the charger is included in the list. To sum up, quadrant IV is the most probable region of operation for the charger. Therefore, our analysis mostly covers comparison of full charging (mode \#3) and full capacitive operation (mode \#2) as two extreme cases and then the combination of the two (mode \#6) is investigated. In the following sections, the charger components that might be affected by the change of the operation modes are studied.

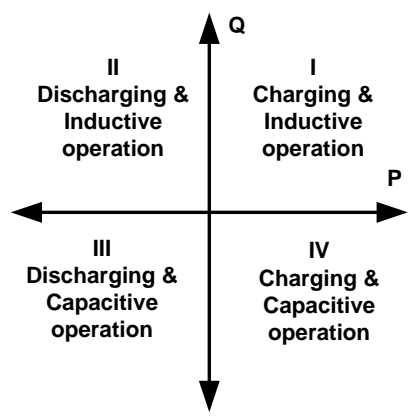

Fig. 5. Operation quadrants of the charger on $\mathrm{P}-\mathrm{Q}$ plane.

\section{A. Effect on Circuit Topology and Control}

Today all of the current PHEVs and EVs use a conventional unidirectional charger whose first stage is a diode bridge rectifier. To allow for bidirectional operation, the diode bridge rectifier must be replaced with controllable switches. The number of switches changes with the operation quadrants. For more discussion on the required updates on the charger topology, please refer to [12].

In addition to the topology change, the controller should also be updated to incorporate the reactive power control in addition to the charging control of the battery.

\section{B. Effect on DC link capacitor}

The basic parameters that define the capacitor selection are the required capacitor current and voltage ratings. The comparison will be made among two extreme conditions, i.e. charging operation and capacitive reactive power operation. It is important to distinguish the low and high frequency current components of the capacitor since the ripple current rating of the capacitor depends on its frequency. The operation mode of the bidirectional charger affects the battery ripple current. By using the analysis in [13], the low frequency ripple current root mean square (rms) value can be found as:

$$
I_{\text {cap }, \text { low }}=\frac{\sqrt{\left(P_{s}^{2} \cdot X_{c}{ }^{2}+\left(V_{s}^{2}-X_{c} \cdot Q_{s}\right)^{2}\right) \times\left(P_{s}^{2}+Q_{s}^{2}\right)}}{\sqrt{2} V_{s}^{2} \cdot V_{d c}},
$$

where $X_{c}$ is the reactance of the coupling inductor [ $\Omega$ ], and $V_{s}$ is the rms value of the grid voltage [V], $P_{s}$ is the active power that is drawn by charger [W], $Q_{s}$ is the reactive power that the charger consumes [VAR], and $V_{d c}$ is the dc link voltage $[\mathrm{V}]$. Equation 1 shows that the power transfer rating as well as the operation mode affects the low frequency capacitor ripple current. Since the bidirectional charger will be operating at different $P_{s}$ and $Q_{s}$ values, it is important to identify the changes seen in the ripple current in different operation modes. It is also important to note that the low frequency capacitor ripple current requirement does not depend on the capacitance, but varies with dc link voltage value.

Once the high frequency and low frequency ripple currents of the dc link capacitor is found, the type of the capacitor (aluminum electrolytic or film), and the size of the capacitor (capacity and volume) can be determined based on manufacturers' data.

Similarly, the dc link voltage, $V_{d c}$ should be greater than a certain threshold to keep modulation index less than one for sinusoidal current supply to the grid. This dc voltage value depends on the phase angle of the charger current. When charging only option, the inverter dc link voltage must be at least:

$$
V_{d c} \geq \sqrt{2} V_{c}
$$

The inverter must supply its maximum output voltage when the charger provides rated reactive power to the grid with the line current phase angle $\theta$ being $90^{\circ}$. Therefore the dc link voltage minimum value for this mode is calculated as follows assuming ideal operation:

$$
V_{d c} \geq \sqrt{2} V_{s}+\sqrt{2} X_{c} I_{c}^{*} .
$$

where $I_{c}{ }^{*}$ is the fundamental component of the line current [A]. In Fig. 6, the minimum dc link voltage values are shown for different coupling inductance values. As shown, the capacitive operation requires a higher dc link voltage than charging operation. This requirement increases with increasing inductor value.

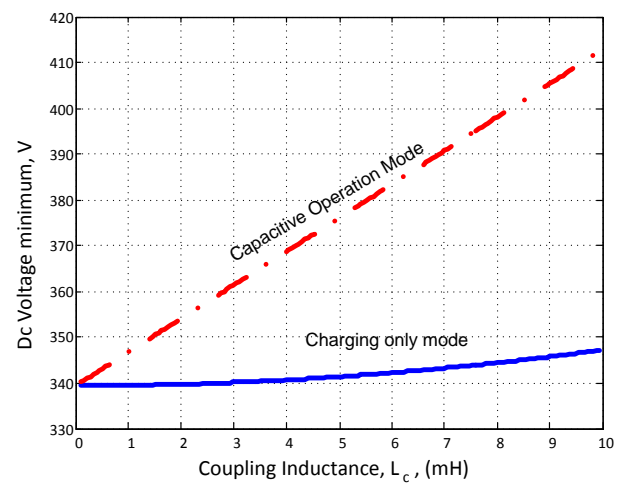

Fig. 6. Minimum dc link voltage requirements of two modes for different inductance values.

While Fig. 6 shows the minimum average values of the dc link, there is also a second harmonic voltage ripple seen in the single phase inverter on the dc link that affects the selection of this voltage. This ripple should also be 
calculated for correct selection of the dc link voltage. Again, this analysis is done in [13], and found as:

$$
\Delta V_{d c}=\frac{\sqrt{\left(P_{s}^{2} \cdot X_{c}{ }^{2}+\left(V_{s}^{2}-X_{c} \cdot Q_{s}\right)^{2}\right) \times\left(P_{s}^{2}+Q_{s}{ }^{2}\right)}}{V_{s}{ }^{2} \cdot \omega \cdot C_{d c} \cdot V_{d c}} .
$$

If the charger is assumed to operate with full capacitive operation, i.e. mode $\# 2, Q_{s}$ becomes negative and voltage ripple becomes the highest. Therefore, increased voltage ripple should be expected for that operation.

\section{Effect on AC-DC Converter Losses}

The ac-dc converter losses are very much related to the converter parameters and the specific modulation that is in use. With careful selection of the parameters, the total charger size can be minimized. However, in this study the motivation is to see if the reactive power operation changes the ac-dc converter losses compared to the baseline charging only operation mode. If this is the case, then the reactive power operation will increase the cooling requirement of the switches and the extra power loss will need to be supplied by the grid. The simulation results are listed in the next section.

\section{Effect on Coupling Inductor Design}

The coupling inductor $\left(L_{c}\right.$ in Fig. 4$)$ design parameters are required inductance value, $L_{c}$, the maximum line current, $i_{c_{-} \max }$ and maximum rms line current, $I_{c_{-} \max }$. Based on these requirements, core type and size, wire size, and total volume are determined. The inductor value $L_{c}$ is a design and control parameter and is selected in combination with other system parameters such as switching frequency and dc link capacitor value. However, when charger operates at its rated power, $i_{c_{-} \max }$ and $I_{c_{-} \max }$ are the same for all operation modes listed in Table 2.

\section{E. Effect on the Battery Current and Voltage}

All of the operation modes of Table 2 except \#1 and \#2 involve the battery. When the battery is not charging/discharging, then it is not connected to the dc link at all. However, when there is reactive power compensation with battery charging/discharging, then both dc-dc converter and ac-dc converter operate together. The dc-dc converter is solely controlled to achieve the accurate charging profile of the battery, i.e. CC-CV charging. Whereas, ac-dc converter is controlled to draw/provide the required grid current both for (dis)charging action and for required reactive power compensation.

As described in the previous sections, reactive power operation mostly affects the dc link parameters, such as dc link voltage requirement, and second harmonic ripple. When there is simultaneous reactive power and (dis)charging operation, the deviation in the second harmonic dc link magnitude should not be reflected on the battery to make sure that the charging current and voltage are not affected by the reactive power operation. This is done by correct selection of the dc-dc converter circuit and feedback parameters.

Reactive power operation of the ac-dc converter also requires some active power to compensate for the losses of the rectifier. This amount is drawn from the grid and the battery is not affected. The simulation results show more detail about this discussion.

\section{Simulation Results}

This simulation study investigates three main operation modes, namely, mode \#2, mode \#3, and mode \#6. Table 3 lists the steady state operation modes of the system.

Table 3. Simulation study parameters.

\begin{tabular}{|l|c|l|l|l|}
\hline $\begin{array}{l}\text { Operation } \\
\text { mode }\end{array}$ & $\begin{array}{l}\text { Active } \\
\text { power }\end{array}$ & $\begin{array}{l}\text { Reactive } \\
\text { power }\end{array}$ & $\begin{array}{l}\text { Rated } \\
\text { power }\end{array}$ & $\begin{array}{l}\text { Simulation } \\
\text { time }\end{array}$ \\
\hline $\begin{array}{l}\text { Mode \#3 } \\
\text { (baseline) }\end{array}$ & $3 \mathrm{~kW}$ & $0 \mathrm{kVAR}$ & $3 \mathrm{kVA}$ & $0-2 \mathrm{~s}$ \\
\hline Mode \#6 & $2.12 \mathrm{~kW}$ & $-2.12 \mathrm{kVAR}$ & $3 \mathrm{kVA}$ & $2-4 \mathrm{~s}$ \\
\hline Mode \#2 & $0 \mathrm{~kW}$ & $-3 \mathrm{kVAR}$ & $3 \mathrm{kVA}$ & $4-6 \mathrm{~s}$ \\
\hline
\end{tabular}

The charger model simulated here is an ideal timedomain switching model. However, the ac-dc converter power losses are calculated and showed separately to investigate the effect of reactive power operation. The passive components are ideal and do not contribute to the loss calculation. The ac-dc converter is controlled using hysteresis current control modulation described in $[14,15]$. The dc-dc converter operates in buck mode since the main focus of this simulation study is to investigate the reactive power operation compared to the baseline charging operation mode. Table 4 shows the parameters of the charger.

Table 4. Charger component parameters.

\begin{tabular}{|l|c|c|}
\hline \multicolumn{1}{|c|}{ Parameter name } & $\begin{array}{c}\text { Parameter } \\
\text { symbol }^{1}\end{array}$ & Value \\
\hline Grid voltage & $V_{s}$ & $240 \mathrm{~V}(\mathrm{rms})$ \\
\hline AC inductor & $L_{c}$ & $1500 \mu \mathrm{H}$ \\
\hline DC link capacitor & $C_{d c}$ & $2200 \mu \mathrm{F}$ \\
\hline DC link voltage & $V_{d c}$ & $500 \mathrm{~V}$ \\
\hline Filter capacitor & $C_{f}$ & $416 \mu \mathrm{F}$ \\
\hline Filter inductor & $L_{f}$ & $300 \mu \mathrm{H}$ \\
\hline $\begin{array}{l}\text { Switching frequency } \\
\text { of dc-dc converter }\end{array}$ & $f_{s w}$ & $40 \mathrm{kHz}$ \\
\hline \multicolumn{2}{|l|}{ Symbols refer to Fig. 4 and derived equations. }
\end{tabular}

The battery is modeled using the charging data presented in Fig. 2. The initial SOC of the battery is selected to be $40 \%$ which corresponds to $200 \mathrm{~V}$ initial terminal voltage. The pack is composed of five parallel strings of 60 serially connected battery cells. Each cell has $3.3 \mathrm{~V}$ rated voltage.

In our simulation analysis, the first operation mode is charging only mode (mode \#3 in Table 2). The battery is charged with almost $3 \mathrm{~kW}$ charging power with constant current charging. The required charging power would increase as the charging continues for hours. Since the battery pack terminal voltage increases, the required input power increases as well. 
The simulation is a time domain simulation and therefore only the first two seconds were simulated in mode \#3. However, two seconds are enough to investigate converter variables since they reach steady state values within this time frime.

Fig. 7 and Fig. 8 show the converter active and reactive power measured at the interconnection of the grid and the converter, respectively. Positive sign means the power is consumed by the charger, and negative sign means the power is sent back to the grid.

\section{A. Battery Current}

Fig. 9 shows how the battery current changes during the simulation. It is showed that the current ripple is not increased during mode \# 6 compared to baseline mode \#3. This confirms that the battery is not impacted by reactive power operation. This is due to successful filtering of second harmonic voltage at the dc link by the dc-dc converter. Therefore, when the charger supplies reactive power to the grid when the battery is under charging operation, the battery is not impacted by this extra operation of the circuit.

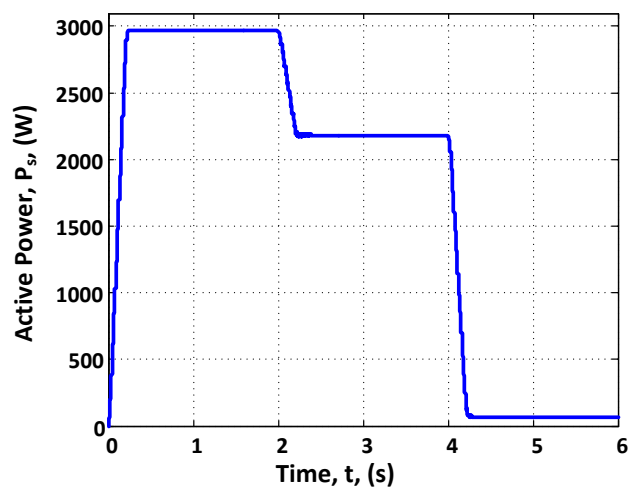

Fig. 7. Active power drawn by the charger.

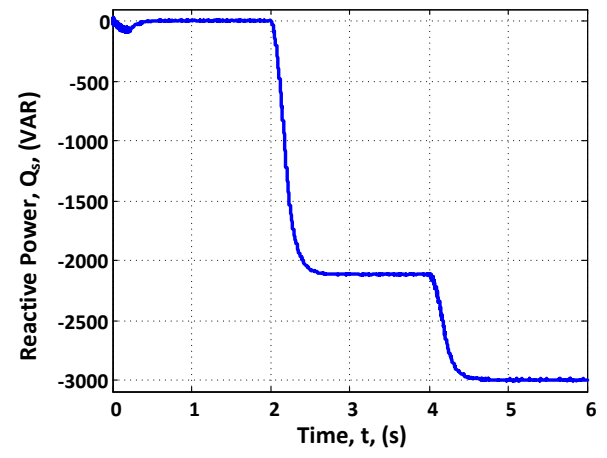

Fig. 8. Reactive power drawn by the charger.

\section{B. AC Inductor Current}

The current that is drawn from the grid is shown in Fig. 10. The maximum line current is limited by the charger rating as shown. Fig. 11 shows a zoomed in version, how the line current changes from one mode of operation to another. As shown, it does not deviate from its sinusoidal waveform as it moves from baseline operation to other operation modes that involve reactive power transfer. At all operation modes, the charger drew a line current with a total harmonic distortion (THD) less than $5 \%$.

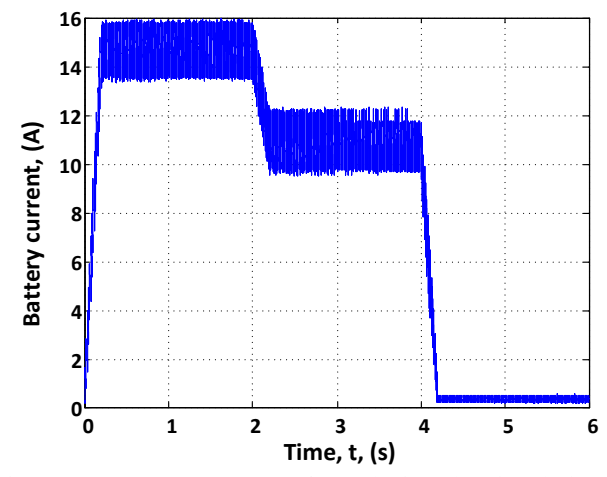

Fig. 9. Battery current waveform during the simulation.

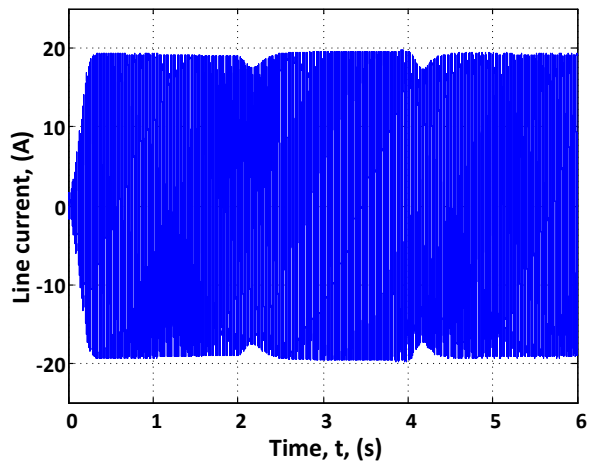

Fig. 10. Complete line current waveform throughout the simulation.

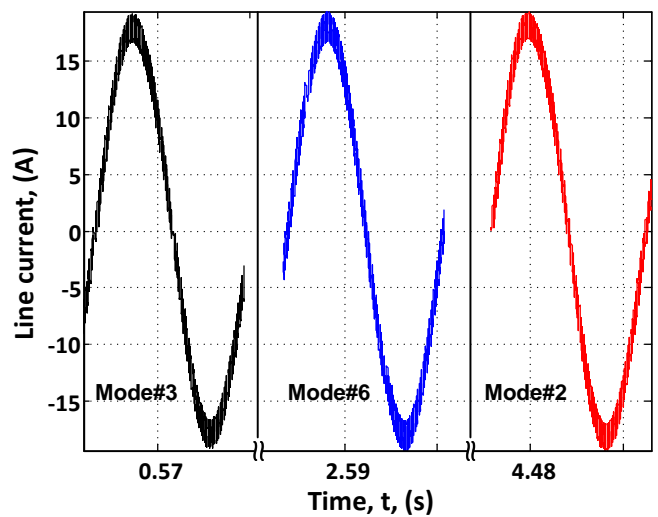

Fig. 11. Zoomed line current for the three modes.

\section{AC-DC Converter Losses}

The result of the simulation study is listed in Table 5. As shown, there is a negligible increase in conduction losses of the ac-dc converter during reactive power operation compared to baseline charging operation. Therefore, full reactive power operation do not require additional cooling other that what is already available for the charging circuit. 
Table 5. AC-DC converter losses for different operation modes.

\begin{tabular}{|l|c|c|l|c|}
\hline $\begin{array}{l}\text { Operation } \\
\text { mode }\end{array}$ & $\begin{array}{l}\text { Switching } \\
\text { losses }\end{array}$ & $\begin{array}{l}\text { Conduction } \\
\text { losses }\end{array}$ & $\begin{array}{l}\text { Total } \\
\text { Losses }\end{array}$ & $\begin{array}{l}\text { Simulation } \\
\text { time }\end{array}$ \\
\hline $\begin{array}{l}\text { Mode \#3 } \\
\text { (baseline) }\end{array}$ & $28 \mathrm{~W}$ & $18 \mathrm{~W}$ & $46 \mathrm{~W}$ & $0-2 \mathrm{~s}$ \\
\hline Mode \#6 & $28 \mathrm{~W}$ & $22 \mathrm{~W}$ & $50 \mathrm{~W}$ & $2-4 \mathrm{~s}$ \\
\hline Mode \#2 & $28 \mathrm{~W}$ & $21 \mathrm{~W}$ & $49 \mathrm{~W}$ & $4-6 \mathrm{~s}$ \\
\hline
\end{tabular}

\section{Capacitor Current}

The last component to investigate for reactive power effect is the dc link capacitor. As described in the last section, capacitor voltage is adversely affected by the reactive power operation due to the increased dc link voltage requirement.

On the other hand, capacitor current is harder to analyze. The capacitor receives current from the ac-dc converter and supplies current to the dc-dc converter. This depends on the switching times of the two converters. In this study, the ac-dc converter operated with a variable frequency switching scheme (hysteresis current control) whereas the dc-dc converter operated at a constant switching frequency. Therefore, converters switch without a synchronism with each other.

It is important to distinguish the low and high frequency current components of the capacitor since the ripple current rating of the capacitor depends on its frequency. After the simulation of the three cases, the results are listed in Table 6.

For all of the cases, the simulation results are compared with the analysis results for the $120 \mathrm{~Hz}$ ripple current case. The analysis results are in very close vicinity of the simulation results. Therefore, it is possible to compute the $120 \mathrm{~Hz}$ ripple current without time domain simulation.

With the selected circuit parameters, reactive power operation case requires only a $2.4 \%$ increase in the second harmonic ripple current compared to baseline case. For high frequency ripples, it is not possible to derive an analytical equation considering the asynchronous switching between the two converters. However, based on the timedomain simulation study, Table 6 shows that high frequency capacitor current is dominant where the charger charges the battery. Reactive power operation mode required $75 \%$ less dc link capacitor high frequency ripple current compared to charging mode. Therefore, it greatly increases the dc link capacitor size. In conclusion, compared to charging operation, reactive power operation mode does not require an increase in the dc link capacitor current requirement.

Table 6. Capacitor current ripple rms values.

\begin{tabular}{|c|l|c|c|c|}
\hline \multicolumn{2}{|c|}{ Ripple Current Type } & $\begin{array}{c}\text { Mode \#3 } \\
\text { (baseline) }\end{array}$ & Mode \#6 & Mode \#2 \\
\hline $\begin{array}{c}120 \mathrm{~Hz}-l \text { low } \\
\text { frequency }\end{array}$ & Simulation & $4.2 \mathrm{~A}$ & $4.3 \mathrm{~A}$ & $4.3 \mathrm{~A}$ \\
\cline { 2 - 5 } & Analytical & $4.2 \mathrm{~A}$ & $4.3 \mathrm{~A}$ & $4.3 \mathrm{~A}$ \\
\hline \multicolumn{2}{|c|}{ Total ripple RMS } & $10.2 \mathrm{~A}$ & $9.1 \mathrm{~A}$ & $6.9 \mathrm{~A}$ \\
\hline \multicolumn{2}{|c|}{ Remaining ripple $>20 \mathrm{kHz}$} & $9.3 \mathrm{~A}$ & $7.8 \mathrm{~A}$ & $5.3 \mathrm{~A}$ \\
\hline
\end{tabular}

\section{CONCLUSIONS}

Based on our study, the bidirectional operation of the $\mathrm{PHEV} / \mathrm{EV}$ charger mainly affects the topology of the charger. Moreover, since the charger operates in fourquadrant, it needs an ac-dc converter that will support bidirectional power flow. However, the conventional $\mathrm{PHEV} / \mathrm{EV}$ chargers do not employ four-quadrant operation, and hence, only a bridge diode rectifier is used at the front end. The control system will also need an update since the inverter has to be controlled to realize reactive power operation.

Second, the voltage rating of the dc-link capacitor increases due to increased voltage requirement in reactive power operation mode compared to charging only operation. However, this increase is only $3 \%$ based on the design parameters of this study.

Compared to charging operation, the current ripple rating of the dc link capacitor is more than enough for reactive power operation. The total losses seen in the ac-dc converter have increased only by 4 watts with reactive power operation. The current of the input inductor is not affected at all.

The battery is not affected with the reactive power operation. In modes \#1 and \#2, since the dc-dc converter is totally disconnected from the grid, there is no effect on the battery. In modes $\# 5$ - \#8, the reactive power operation is achieved and the battery is charged/discharged without any distortion due to the reactive power operation. The only limitation here is that since the line current is limited, if there is any reactive power support to the grid, then the battery current needs to be adjusted so that the maximum line current is not exceeded.

In conclusion, for this specific charger topology, the reactive power operation is achieved without any considerable changes compared to charging only operation of the system.

Considering that the EV/PHEV battery chargers will be an integral part of the distribution system in near future, the effects of using them as advanced power controllers should be analyzed in both grid perspective and in charger/vehicle perspective. While there are many benefits of sending active/reactive power back to the grid, the changes in the design of the charger and adverse effects on the operation of the battery should be well defined to fully understand the system merits. This study summarizes the effect of four-quadrant operation modes on the charger and presents the simulation results to show the effects of different operation modes. 


\section{REFERENCES}

[1] "International Energy Outlook 2009," Energy Information Administration (EIA), Office of Integrated Analysis and Forecasting, U.S. Department of Energy, OE/EIA-0484(2009), May 2009.

http://www.eia.doe/gov/oiaf/ieo/pdf/0484(2009).pdf

Available:

[2] $(2011, \quad$ January). Mitsubishi MiEV. http://www.mitsubishi-motors.com/special/ev/whatis/index.html

[3] (2011, January). BYD Auto. Available: http://www.byd.com/showroom.php?car=f3dm

[4] (2011, January ). Tesla Motors. Available: http://www.teslamotors.com/goelectric/charging

[5] (2010, August). 2011 Chevrolet Volt Plug-in Hybrid Electric Car. Available:

http://www.chevrolet.com/pages/open/default/future/volt.do

[6] (2010, August). Nissan Leaf Electric Car. Available: http://www.nissanusa.com/leaf-electric-car/index\#/leaf-electriccar/index

[7] M. Kuss, T. Markel, and W. Kramer, "Application of Distribution Transformer Thermal Life Models to Electrified Vehicle Charging Loads Using Monte-Carlo Method " presented at the 25th World Battery, Hybrid and Fuel Cell Electric Vehicle Symposium \& Exhibition Shenzhen, China 2010.
[8] J. Voelcker. (2007, September) Lithium batteries take to the road. IEEE Spectrum. 27-31.

[9] (2008, August). Lithium Ion. Available: http://www.sanyo.com

[10] "SAE electric vehicle and plug-in hybrid electric vehicle conductive charge coupler ", ed: SAE International, 2010.

[11] E. Partington, "Plug-in hybrid electric vehicle charging systems Battery chargers," in The Bussiness of Plugging In, Detroit Michigan, 2010

[12] M. C. Kisacikoglu, A. Bedir, B. Ozpineci, and L. M. Tolbert, "PHEV-EV Charger Technology Assessment with an Emphasis on V2G Operation," Oak Ridge National Laboratory,to be published in 2011.

[13] M. C. Kisacikoglu, B. Ozpineci, and L. M. Tolbert, "Effects of V2G Reactive Power Compensation on the Component Selection in an EV or PHEV Bidirectional Charger," in IEEE Energy Conversion and Congress Exposition, Atlanta, GA, 2010, pp. 870-876.

[14] M. C. Kisacikoglu, B. Ozpineci, L. M. Tolbert, and F. Wang, "Single-phase inverter design for $\mathrm{V} 2 \mathrm{G}$ reactive power compensation " in Applied Power Electronics Conference, Fort Worth, TX, 2011, pp. $808-814$.

[15] P. A. Dahono, "New hysteresis current controller for single-phase full-bridge inverters," IET Power Electron., vol. 2, no. 5, pp. 585 594,2009 